\title{
An Overview of Educational Policies of Pakistan (1947-2020)
}

\author{
Zeeshan Ahmed ${ }^{1}$, Sarfraz Khan ${ }^{2 *}$, Sadia Saeed ${ }^{3}$ and Syed Imran Haider \\ ${ }^{1}$ PhD Scholar, Department of Sociology, Quaid-i-Azam University, Islamabad Pakistan \\ ${ }^{2,3}$ Assistant Professor, Department of Sociology, Quaid-i-Azam University, Islamabad Pakistan \\ ${ }^{4}$ Assistant Professor, Department of Sociology, Allama Iqbal Open University, Islamabad, Pakistan \\ *Corresponding Author's Email: sarfraz@qau.edu.pk
}

\begin{abstract}
Education is considered as a key to achieve socio-economic prosperity around the globe. The quality of education depends upon country's educational policy. Countries with a better educational policies and a continued funding can better attain the socio-economic development with an ease. Whereas, countries like Pakistan, despite its several educational policies, is yet to achieve the milestone of socio-economic development. The reasons for such failure may be regarded to partial or complete catastrophe in policy implementation. Moreover, factors like political and bureaucratic reluctance, weaker economy, inconsistency in policy implementation, clash of political ideologies, wars, toppled regimes and above all corruption have been among the major factors of failure. For the attainment of economic and social prosperity, Pakistan needs to introduce a uniform policy along with qualified staff for inculcating the curriculum and either local or national language for more conceptual clarity. Moreover, the most important step is the allocation of funds required minimum 4\% budget of GDP for education with serious attitude of bureaucracy, political will and consistency or else the vision of achieving social and economic uplift seems to remain a dream rather than a reality.
\end{abstract}

Keywords: Education; Uniform Policy; Educational Uplift; Social and Economic Prosperity; Pakistan.

Article Received: 18 October 2020, Revised: 3 November 2020, Accepted: 24 December 2020

\section{INTRODUCTION}

Since the birth of humankind the learning process has been marked as a prime feature for the survival and betterment. As the survival of human greatly depended upon the fulfilment of the basic needs for which they employed different strategies and tools such as seeking shelter in caves, tools for protection and cultivation and thereby tried to inculcate similar knowledge and experiences to their younger generations. The attempt to transfer already existing knowledge and experiences may be regarded as foundation of education. The duck worth pages of history reveal that education has always been responsible for the socio-economic uplift of the society and thereby occupies the position of basic needs. Despite the significant role of education in human development, the promotion of education, its funding and construction have remained a challenge for the world particularly for the lesser developed countries.

The data reveals that in spite of its (education) inclusion in UN declaration of 1947 which declares education as basic right to all the children. However, on contrary to the UN declaration, 124 million children in the world are still unenrolled while 250 million are incapable to acquire rudimentary skills on account of the pitiable quality of schooling. Moreover, the situation is even worst for girls, disable children and ethnic/ racial minorities who are denied access to education. The denial of admittance and underprivileged quality of learning has far reaching consequences on their futures and those on their families, communities and above all countries. Education, is characteristically professed as the leading contributor to augmentation in human capital, public health measures which eradicate or reduce the continuing effects of devastating diseases and dietary enhancements which protect against impairment of cognitive skills in the young also add to human capital development [1].

Considering the importance of education and research the developed countries on one hand have been able to allocate major part of their GDP and succeeded in promoting education to the greatest extent whereas on contrary to the developed world, the emerging nations in Asia allocate two to three times higher budget on education which is almost equalling to their expenditure on health [1]. Pakistan has the second largest population for out of school children. The number of out of school teen-agers is projected to 22.8 million children during 2019-20 [2]. Moreover, a recent report about Pakistan counted that 5 million children [2] between the age of 5-9 are not admitted in schools and after primary- school age, the number of out of school children doubles, with 11.4 million adolescents between the ages of 10-14 not receiving formal education [3]. Disproportions in terms of gender, socio-economic eminence, and geography are momentous; in Sindh, $52 \%$ of the deprived children (58\% girls) are yet to be enrolled, and in Balochistan, 78\% of girls are out of school [2].

Despite aforementioned high number for out of school children in Pakistan, the government still seems to be ignoring the particular component of education. During the year 2020-21, the government allocated 83.3 billion rupees. Previously the allocated official budget for education was 81.2 billion. Although, the allocated educational budget for the year 2020-21 indicates an increase by $2.5 \%$, the allocated educational budget hardly makes $2.3 \%$ of Pakistan's GDP. Considering the set international standard 
as of decided allocation of $15-20 \%$ of over-all while $4 \%$ of the GDP, the allocated budget for schooling in Pakistan may be declared as the lowest in the region [3].

From the aforementioned discussion it may be asserted that education and educational quality in Pakistan in terms of budget allocation, educational sector seems to be on secondary levels. Such an approach towards education poses serious concerns about future generations, economy and development of Pakistan. Furthermore, despite the first conference on education soon after the inception of Pakistan as a separate state, being lower and second largest in terms of out of school children and educational budget poses serious concerns about educational policies and efforts for promotion of quality education in Pakistan. This particular study aims at finding the answers to the posed questions regarding education and moreover reviews of the educational policies of Pakistan their impact and pitfalls in weakening/downfall of educational standard in Pakistan.

\section{Problem Statement}

Since education is considered as the key to the stability and development of society. Therefore, almost all the countries across the globe allocate major share of GDP for education including enhancement of educational quality, updating curriculum and bringing pedagogical and learning innovations. Based on the aforementioned measures the countries have not only attained the socio-economic developed but have also ensured stability. Pakistan is also among the countries which soon after inception prioritized education and thereby introduced its educational policy. However, its noteworthy here that Pakistan despite prioritizing education, the educational system and educational policies in Pakistan are on a decline. Here the question arises that despite implementation of 9 major educational policies, why the quality of education is on a decline? Furthermore, how and why all the educational policies couldn't play an effective role in enhancement of quality education? Moreover, to what extent the educational policies were carried on by the successive governments in Pakistan? To address these questions in the case of Pakistan the current articles was written.

\section{Objectives of the Study}

There were mainly two objectives of the study:

- To review the educational policies of Pakistan from 1947 till the year 2020.

- To critically analyze the educational policies and their implementation.

\section{METHODOLOGY}

The current research article is purely based on the secondary data analysis depending on the already published research reports by the Government of Pakistan or some other organizations like the United Nations. In addition to that we have also consulted the individual/independent research papers as well, since the sole purpose of this analysis was to give a clear picture of the educational policies in the case of Pakistan. So, we accessed all such articles/reports through web search while using the various keywords within the scope of our study.

\section{RESULTS AND DISCUSSIONS}

\section{Educational Policies of Pakistan (1947-2020)}

Since its inception, Pakistan has been organizing educational conferences. The purpose of these conferences was to improve already weaker educational system. The following discussion is mainly based on the review of main agenda points of all educational conferences organized by the Government of Pakistan from 1947-2020.

Educational Policy of Pakistan (1947-1959)- The country's first conference on education was held in 1947 in which initial directions for revision of curriculum were introduced for the first time. So that country's educational system could be reconstructed. Moreover, the purpose of the conference was to shape the educational system as per the social, cultural and economic needs of the country [4]. Furthermore, the chairman of the first educational conference (Muhammed Ali Jinnah- The first governor general of Pakistan also known as Quaid-i-Azam- "Great Leader") set up various committees which may be described as (a) Scientific Research and Technical Education Committee, (b) Adult Education Committee, (c) University Education Committee, (d) Primary and Secondary Education Committee, (e) University Education and Primary and Secondary Education, (f) Women's Education Committee, (g) Committee for Scheduled Caste and Backward Classes Education, (h) Cultural Relations Committee, (i) Joint Meeting of the Committees on the University Education, Scientific Research and Technical Education and Cultural Contacts, and (j) Joint Meeting of the Committees on University Education, Women's Education and Primary and Secondary Education. All the established committees were assigned the task to review the loopholes of the educational system and prepare the recommendations to improve the educational quality in the country.

All the committees submitted their reports in November 1947 [5]. However, the first educational conference and the recommendations by the educational committees couldn't be implemented due to several factors prominently political and leadership crisis due to the death of Quaid-i-Azam. Furthermore, the war of 1948 between India and Pakistan also asserted to have paused the implementation. Moreover, focus of the political leadership was mainly to the formation of constitution for the country so issues like education could hardly receive any attention [5].

Educational Policy of 1959- Following a resolution approved by government of Pakistan in December 1958 then President General Ayub Khan appointed National Commission on Education. The commission was properly inducted on $5^{\text {th }}$ January, 1959. The President ordered the 
commission to recommend initiatives for mobilizing the preeminent uses of its existing human and state wealth. In preparing its suggestions, he urged upon the commission to take into consideration the inadequate assets of the state [4]. The members of the commission based on almost all aspects of education prepared a questionnaire and distributed and reproduced in newspaper widely to all the institutions across Pakistan. In addition to this various individual submitted their feedbacks regarding all the aspects of educational system of the country. Apart from this commission in order to take inputs from renowned educationists from East and West Pakistan were called on by the commission in February and April 1959. Moreover, the members of the commission also had extensive discussions on shared feedbacks and recommendations, the discussion sessions were also participated by Dr. Herman B. Wells, President of Indiana University, Bloomington, USA, and Dr. John C. Warner, President, Carnegie Institute of Technology, Pittsburgh, USA. Including two prominent Pakistani professors, Dr. I. H. Qureshi, Professor of History, and Dr. Abdus Salam, Professor of Applied Mathematics [4].

It was orated that schooling system must associate constructively with other systems. To assist it in making these comparisons, the commission requested a number of people to work as consultants and to prepare documentary evidence and secure data [5]. The report consisted of various features some of them were declaring education compulsory till the age of 10 years [5]. Furthermore, religious education was also declared necessary in addition to compulsory education the commission also urged upon the equivalent extension of boys' and girls' education [4]. Whereas the other recommendations of the commission included character construction, essential primary education focus on science and methodical education, national language as medium of instruction, three-year degree program, eradication of illiteracy, formation of academe grants commission, amalgamation of inner (25\%) and exterior $(75 \%)$ assessment in examination structure and introduction of religious education at three levels, (a) essential at middle level, (b) elective at advanced secondary level while research university level. The recommendations of the commission couldn't be implemented due to inadequate capital and disparaging circumstances of the country [5].

Educational Policy of 1970- Considering the failure of previous educational policies, government of Pakistan with the help of educational commission of Pakistan introduced its third five-year plan from 1965-1970. Unlike other plans the focus of this plan remained on more budget allocation for primary education. As per plan, Government of Pakistan allocated 2652 million rupees for the primary education. In addition to this, the plan also stressed upon technological and scientific education so as to produce skilled manpower for the country [6]. Furthermore, national educational policy also known as new educational policy was introduced during General Yahiya Khan's regime. The main focus of the policy was the induction of scientific and technological education, besides that it also urged upon ideological orientation in education. Moreover, the policy also decided to decentralize the education administration and thereby replace that with educational units. Moreover, the policy also declared the year 1980 as target to achieve the goal of compulsory universal free primary education. Based on census data, it was estimated that by the year 1980 almost 100 million people would be literate which would include $90 \%$ people from urban areas while $10 \%$ from the rural areas of Pakistan [7].

Educational Policy of 1972- National educational policy of 1972 was introduced under the supervision of Zulfikar Ali Bhutto on March 29, 1972. The policy mainly incorporated the ideology of Pakistan, equal free and universal education for both male and female up to $10^{\text {th }}$ class. Like other educational policies this educational policy also stressed upon scientific and technological education. Among all the policies this educational policy is said to be the real contributor towards the change in educational system in a true sense [8].

Educational Policy of 1979- This educational policy was introduced during the presidency of Zia-ul- Haq. Due to ZiaUl-Haq's inclination towards religion, it can be asserted that the policy was urged upon possessing and promoting religious ideologies along with the promotion of scientific and technical education. Besides that, the policy also agreed upon giving equal educational opportunities for male and female. In this policy it was also agreed that the curriculum needed to be reviewed. Moreover, it also decided the amalgamation or merger of madrassas and create a linkage between technical and scientific education. Urdu was also declared as medium of instructions with separate educational institute for males and female across Pakistan [9].

Educational Policy of 1992- The educational policy of 1992 was based on recommendations and proposals of educational conference held during April, 1992. The educational policy mainly included the inputs by educationists, scholars, scientists, writers, teachers, newspaper editors and lawyers across Pakistan. After indepth debate and discussion, the educational policy was devised. The salient features of the policy consisted of elevation of Islamic tenets through education, betterment in feminine education, preparation of curriculum according to the need of the day. Most importantly the policy decided to expand the duration of graduate and post graduate studies in Pakistan.

National Educational Policy 1998-2010- The educational policy was first introduced under the regime of Mian Muhammad Nawaz Sharif and then General Pervaiz Musharaf after military coup during October, 1999. It was implemented in March 1998. As per the policy Quranic principles and Islamic practices were declared as integral part of the educational curriculum. In addition to this universal primary education, provision of basic educational facilities and opportunities to people with an aim to expand basic education for creating opportunities for higher education in Pakistan [10]. 
National Educational Policy 2009-2015- This particular policy was introduced by Pakistan People's Party (PPP). The preparation of this educational policy had already begun before the party came into power. Moreover, the policy may be differentiated on the basis of in-depth discussions and multiple reviews of the policy. The purpose of review was to prepare an educational policy that could serve to achieve national goals and interests. The policy's focus remains "Early Childhood Education-ECE" which was ignored in almost all the previous educational policies. Under this policy it was proposed that the children from age 3-5 must receive early education before starting formal education from class-1 and enable them for their primary education. Moreover, the non-formal education was deemed necessary for all the adults so that the literacy rate of the country could be improved. In addition to this, the policy also aims at the uplift of educational quality and the target of educational policy could be achieved with the help of six pillars namely teacher, curriculum, textbooks, assessment, learning environment and taking education as important element in their life [11].

National Educational Policy 2017-2025- This policy was introduced and implemented by then regime of Pakistan Muslim League, Nawaz (PML-N). The aim of the policy was to increase public sector colleges and universities in Pakistan. Moreover, it was also suggested to support the private sector universities to uplift their educational standards and increase virtual education across Pakistan. It was also agreed that more sub-campuses of colleges and universities should be established across Pakistan. This particular policy also paid attention towards special education and agreed upon enrollment of $50 \%$ special children by 2025 and also allocated 5\% separate budget for special education across Pakistan $[12,13]$.

\section{Gaps in Educational Policy Implementation of Pakistan}

There are several reasons due to which all the educational conferences and devised policies couldn't be implemented however here we can discuss few major flaws that actually hindered the implementation of educational policies. The major factors that played a part in failure of implementation was that of: (a) poor communication system, (b) feeble management, (c) poor procedure assessment apparatus, (d) financial breaches and loopholes, (e) attitudes and disposition of public servants, (f) inefficient bureaucratic structure, (g) failure of decentralization measures, (h) lack of political will, (i) leadership vacuum, (j) deeply entrenched corruption, (k) military takeover and (l) lack of consistency $[14,15]$. The things could work better for education if these flaws were timely pointed out by the sitting government and addressed amicably.

\section{CONCLUSION}

The above discussion indicates that governments in Pakistan since the inception have been putting efforts to revolutionize/bring reforms in educational sector. However, all such efforts of bringing reforms in educational sector couldn't bore the manifested results and couldn't thereby contribute to the social, economic and educational uplift. The failure of almost all the educational policies may be regarded to the political and economic instability in the form of wars, dictatorships. Besides the aforementioned factors, political and bureaucratic reluctance are also among the factors which resulted in failure of educational policies. Whereas, several other reasons for the failure may be regarded as similarity among policies, influence of leadership ideologies and above all ideological and political rivalry among political parties also the hidden factors for failure. Failure or partial implementation of almost all educational policies turned out to be a great economic and social setback for Pakistan. Since Pakistan couldn't produce skilled labor or even couldn't even make any major breakthrough in the form of inventions or discoveries.

Consequently, Pakistan's status couldn't be changed from economically dependent country to emerging economies. Considering the existing scenario, it is important to introduce a uniform and updated curriculum with trained hiring of well-equipped and qualified teachers. Furthermore, the medium of instruction should also be either in mother tongue or in a national language initially and in English at higher levels so that the students could have conceptual clarity. Moreover, Pakistan also needs to introduce a uniform educational system which should include all other federal and madrasa systems within same categories with minimum $4 \%$ of the country's total GPD for education. The dream of skilled labor, achievement of social and economic prosperity may not come true if we don't properly address the flaws already pointed or even if the funds are not allocated according to the needs.

\section{References}

[1] Dowling, J. M. Jr. (1982). Education as a Human Capital Basic Needs Strategy for Asian LDCs. Southeast Asian Journal of Social Science, 10(2), 13-31.

[2] UNICEF. (2020). Education: Giving every child the right to education. Pakistan: United Nations International Children's Emergency Fund. Retrieved from https://www.unicef.org/pakistan/education\#: :text= Currently\%2C\%20Pakistan\%20has\%20the\%20wor ld's,population\%20in\%20this\%20age\%20group

[3] Pakistan Alliance for Girls Education. (2020). Education budget of Pakistan. Retrieved from https://page.org.pk/education-budget-of-pakistan/

[4] Ahmed, S. (2020). All educational conferences of Pakistan. Retrieved from http://shoaibahmed86.yolasite.com/resources/pep.p df 
[5] Lingard, B., \& Ali, S. (2009). Contextualising education in Pakistan a white paper: Global/national articulations in education policy. Globalization, Societies and Education, 7(3), 237256.

[6] Government of Pakistan (1965). Third five-year plan. Islamabad: Planning Commission, Government of Pakistan.

[7] Government of Pakistan (1970). The new educational policy. Islamabad: Ministry of Education and Scientific Research, Government of Pakistan.

[8] Government of Pakistan (1972). National education policy, 1972. Islamabad: Ministry of Education, Government of Pakistan.

[9] Government of Pakistan (1979). National education policy and implementation programme. Islamabad: Ministry of Education, Government of Pakistan.

[10] Government of Pakistan (1998). National education policy 1998-2010. Islamabad: Ministry of Education, Government of Pakistan.

[11] Government of Pakistan (2009). National education policy, 2009. Islamabad: Ministry of Education, Government of Pakistan

[12] Government of Pakistan (2017). National education policy, 2017. Islamabad: Ministry of Education, Government of Pakistan.

[13] Sajid, A. R. (2012, Dec. 26). Educational policies of Pakistan- where Pakistan stands? The Educationist. Retrieved from http://educationist.com.pk/educational-policies-ofpakistan-where-pakistan-stands/

[14] Ahmed, I., Rauf, M., Imdadullah, Zeb, A. (2012). Implementation gaps in educational policies of Pakistan: Critical analysis of problems and way forward. International Journal of Humanities and Social Science, 2(21), 240-45. http://www.ijhssnet.com/journals/Vol_2_No_21_N ovember_2012/28.pdf

[15] Ahmed, M. Mahmood, T., Mohyuddin, M.S., Ghuman, M.A. (2013). Evolution of school effectiveness of secondary education system: comparative view institutions of Pakistan. Journal of Education and Social Research, 3(3), 121-28. 